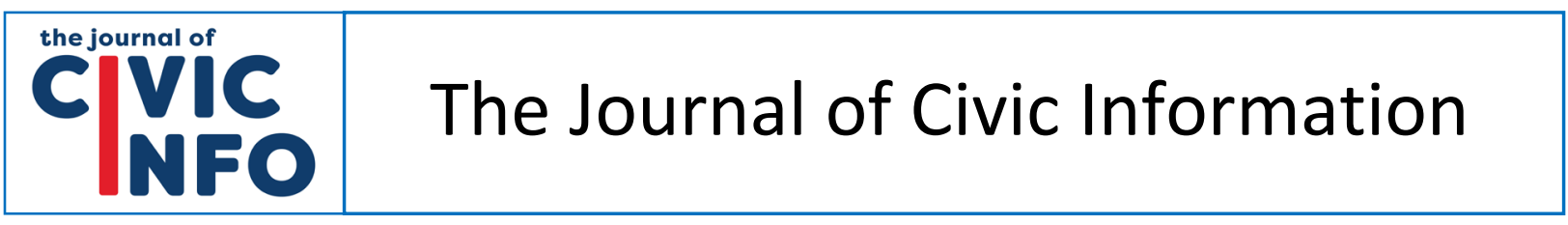

Volume 1 | Number 1

September 2019

Journal homepage: https://journals.flvc.org/civic/

ISSN (online): 2641-970X

\title{
Agency Perspectives on Online Public Records Request Portals
}

\section{Alexa Capeloto *}

\section{Article Information}

Received: Jan. 16, 2019

Accepted: Feb. 13, 2019

Published: Sept. 4, 2019

Keywords

Freedom of information

Public records

Government transparency

Online portals

\begin{abstract}
Spurred by converging trends facilitated by the interactive web, government agencies are moving to digitize and make more transparent the public record request (PRR) process via dual-facing online portals. Such portals, often provided by third-party vendors as SaaS (Software as a Service) solutions, are built on the premise and promise of helping agencies streamline their internal workflows while aiding requesters through the sometimes labyrinthine process of accessing public records. This research aims to study the effects and efficacy of such portals from the agency perspective, both at the process level and in a broader sense of reshaping the relationship between citizen and government. Set within a contextual framework of the trends from which these portals have emerged, a survey of 54 U.S. public jurisdictions suggests that online portals are significantly improving agencies' internal and external processes of receiving, tracking, and responding to requests for public records, but do not necessarily bring correlative improvement in their overall relationship with citizens for a number of possible reasons.
\end{abstract}

* Alexa Capeloto, John Jay College of Criminal Justice, City University of New York. Please send correspondence about this article to Alexa Capeloto at acapeloto@jjay.cuny.edu. An earlier version of this work earned top-three paper at the National Freedom of Information Coalition summit FOI Research Competition, April 12, 2019, in Dallas, Texas.

To cite this article in Bluebook: Alexa Capeloto, Agency Perspectives on Online Public Records Request Portals, 1(1) J. CIVIC INFO 59 (2019).

To cite this article in APA: Capeloto, A. (2019). Agency Perspectives on Online Public Records Request Portals. Journal of Civic Information, 1(1), 59-74. 


\section{Introduction}

Each year, Government Technology magazine publishes its GovTech 100, a list of the top 100 technology companies "focused on, making a difference in, and selling to state and local government agencies across the United States." And each year since the list launched in 2016, the companies GovQA and NextRequest have been included. Chicago-based GovQA was founded in 2002 and offers a variety of software services to public agencies, including subpoena management, inter-agency communications, and a portal for processing public records requests (PRRs). The company has more than 1,000 government clients, and the majority of them utilize the PRR portal, including Dallas, Seattle, and Salt Lake City. NextRequest was founded in 2015 and is focused exclusively on providing agencies with PRR portals. As the San Francisco-based company states on its website: "Public Records Is All We Do." Although newer to the field, NextRequest has quickly amassed a sizeable client list, from small towns, such as Sunny Isles Beach, Florida, and Bourne, Massachusetts, to large cities, including San Francisco, San Diego, and Miami.

Although several other companies exist, GovQA and NextRequest are two of the most common providers of government PRR portals, offering web-based platforms for centralized, automated tracking and processing of information requests submitted by the public under their respective states' freedom of information laws. These services have emerged at the nexus of several digital-age trends, including GovTech, civic tech, operational transparency, and online requester-side PRR aids like MuckRock and iFOIA, yet little has been done to research their impact in the all-important space where transparency is enforced as a means of preserving open, fair government.

To that end, this article examines the effects and efficacy of online freedom of information portals employed by government agencies - with a particular focus on NextRequest as it rapidly builds a client list with the stated goal of restoring trust between citizen and government - and analyzes how such services are in fact reshaping the PRR process for those who manage it day to day.

\section{Background}

\section{Help for requesters}

Transparency is one of the ideological roots of democracy in the United States, enshrined in federal and state freedom of information laws governing one's right of access to public records. Yet obtaining records at the federal, state, and local levels can be a notoriously difficult process, and the frustration continues. A March 2017 study commissioned by the John S. and James L. Knight Foundation surveyed 228 people, including journalists and members of FOI advocacy organizations, about their experiences with records request processes. About half reported that access to state and local records had gotten worse during the previous four years, and nearly 40 percent reported that denial of records had become more frequent at all levels of government, particularly at the local level (Cuillier, 2017). David Greene, senior staff attorney for the Electronic Frontier Foundation, said "it just takes too long" for agencies to respond to requests (p. 7). The same respondents reported dissatisfaction with technology around the PRR process. A third of responders ranked government technology as very or extremely problematic, and 80 percent said it is at least somewhat of a problem (p. 9). 
Identifying a need, several nongovernmental efforts to assist records requesters via technological tools have proven effective. Asked for the Knight Foundation report to identify the most useful FOI digital tool, 27 respondents named MuckRock, by far the most popular answer (Cuillier, 2017, p. 41). MuckRock is a nonprofit news site that aids requesters through the process of filing for information from government agencies, while also providing a repository of responsive documents and conducting original reporting and analysis around those documents. The stated goal is to "mak(e) politics more transparent and democracies more informed" ("About MuckRock," para. 1). As of September 2019, the nonprofit had logged more than 68,000 requests filed with 13,714 agencies, resulting in more than 20,000 fulfilled requests yielding 4.3 million released pages. As Boston magazine put it, "the company is doing for public records what TurboTax did for taxes or Change.org did for petitions: making it easier to be an engaged citizen" (Eil, 2016, para. 29).

In 2016, MuckRock took over the records request tool FOIA Machine, which had been seeded by the Knight Foundation and a Kickstarter campaign. While MuckRock offers "full service" assistance for a cost, such as directly filing requests with agencies, conducting follow-ups and digitizing responsive records, FOIA Machine continues to offer free assistance with generating and tracking one's requests (Wang, 2016). Both are built on open-source software, as is Alavateli, a UK-based online tool that helps with making and tracking requests. Other requester-assistance services include iFOIA.org, from the Reporters Committee for Freedom of the Press, and a requestletter generator provided by the Student Press Law Center.

As these services facilitate PRRs filed with public agencies, the agencies must find a way to keep up on their end. This link is mentioned in the Knight Foundation report, attributed to a cofounder of NextRequest:

As more online tools, such as MuckRock, make it easier for people to request records, it seems likely agencies (especially those that have not digitized operations) will have even greater difficulty responding, said Tamara Manik-Perlman, chief executive officer of NextRequest. "People impute ill will on the state-local level, but most of the time people are just overburdened and just don't have time to do what they need to do," she said. (Cuillier, 2017, p. 25)

\section{Governments get involved}

Fulfilling requests on the agency side can be just as frustrating as asking for them on the constituent side. Records managers for this research reported a range of cumbersome processes for handling requests prior to adopting PRR portals. Most involved a mix of paper forms, spreadsheets, and email communication. As one survey respondent described it: "Excel spreadsheets, lots of calendars, a lot more confusion, and missed deadlines." Silo-ization, in which PRR management was left to individual departments, added to the confusion, as another respondent stated:

Disjointed, to say the least. Anyone within a department would receive a records request and would sometimes coordinate within their own department, and even less frequently they would coordinate with other departments to retrieve responsive records. When there was a request that spanned multiple departments, not only would multiple departments disclose documents, but the requester would receive multiple responses, often times producing duplicate records and conflicting responses as far as exemptions. 
Faced with frustration from requesters and hoping to ameliorate a persistent pain point, some agencies adopted a system similar in structure to MuckRock and FOIA Machine but created for the government side of the PRR transaction.

In 2013, fellows with the Code for America program teamed with the city of Oakland to develop RecordTrac, an open-source software tool to help the city manage the voluminous requests filed under the California Public Records Act in the wake of the 2011 Occupy protests. Together they built a dual-facing system that on one side allowed city staffers to receive and track PRRs across departments, and on the other side provided a simple interface for users to make and track their own requests. Users were told who at the city was handling their request and how to contact them. Responsive documents were not only shared with requesters, but published in a searchable repository in a "release to one, release to all" approach. Oakland officials estimated that the number of records requests more than doubled during RecordTrac's first year of operation (Capeloto, 2014). The system was named 2013 Civic App of the Year by GovFresh (Fretwell, 2013), and dubbed America's best FOI website by the New York open-government nonprofit Reinvent Albany (“America's Best," 2014).

Like MuckRock and FOIA Machine, RecordTrac was built on open-source software. The developers put the source code on GitHub for other agencies to adapt and adopt. A web developer with the city of Yakima, Washington, replicated the portal with essentially the same features and functions (Capeloto, 2014). New York City developers rewrote the code to suit their agencies' scale and needs, and launched their own beta version, called OpenRECORDS, in 2015. A newer version, released in 2017, is used by 38 city agencies and counting ("About OpenRECORDS").

The PRR process had been moving online long before this. In a 2011 Electronic Government survey conducted of municipal agencies by the International City/County Management Association, 50 percent of respondents said they allowed for online records requests (Norris \& Reddick, 2011, p. 3). In 2017, 44.8\% said they provide an "off the shelf" technology solution for public records requests (International City/County Management Association, 2017, p. 5). In addition to GovQA, which began selling its various software suites exclusively to government clients about 10 years ago, several other systems were listed by agencies surveyed for this research, some of them dedicated PRR tools and others used in adapted form for records management.

RecordTrac earned attention as a Code for America project. In general, government technology, or GovTech, is primarily "designed with government as the intended customer or user," while civic technology, or civic tech, is "technology used to inform, engage and connect residents with government and one another to advance civic outcomes" (Knight Foundation and Rita Allen Foundation, 2017, p. 7). GovTech is defined by the intended user (government) and focused on increasing internal operational efficiency, while civic tech usually includes a citizenfacing component (Knight Foundation and Rita Allen Foundation, 2017, p. 7) and understands both government and public to be core partners (Shaw, 2016, para. 12). For a long time, civic tech primarily referred to nongovernmental initiatives, but Code for America allowed for civic citizenfocused technology to be "developed and implemented by and with public bodies themselves in an attempt to reach out to citizens and increase engagement and participation" (Rumbul \& Shaw, 2017, p. 1). With RecordTrac, technologists and policymakers worked together to simplify and optimize the PRR process, and developers paid particular attention to user experience just as a service like MuckRock would. The "release to one, release to all" concept, for example, was explained by a RecordTrac developer this way: "Prior to [the project], I didn't know what FOIA 
was, so I didn't come in with preconceptions about it. ... I wanted to do the most simple design possible, so that's why everything is public" (Rumbul \& Shaw, 2016, p. 22).

Parker Higgins, director of special projects for the Freedom of the Press Foundation, explored RecordTrac in 2015 and described the "very cool" experience of combing through readily available datasets. "If all this seems familiar," he wrote, "it may be because services like Muckrock, where I'm a frequent user, have implemented the same kind of thing on the requester end" (para. 5). He added, "Muckrock definitely makes the public records experience better, and has built an impressive collection of returned documents. But there's an emergent property of the agencies themselves putting all that information online in the first place" (para. 6).

\section{The emergence of NextRequest}

Open-source software is free, transparent, and adaptable, but it can languish without proper funding, staffing, or maintenance structures. One Oakland program manager told a researcher that the city's contracting policies are structured around multimillion-dollar deals, not the smaller ongoing maintenance RecordTrac required (Rumbul \& Shaw, 2016, pp. 32-33). As an internal city memo noted:

The City has no in-house capability to maintain the current RecordTrac system. Since our current RecordTrac software is also not supported, it is impossible to make much needed software updates. The lack of support could result in a system-wide failure of the entire public records system. Ultimately, we decided that while we love RecordTrac, we love transparency more. (City of Oakland, n.d.).

Richa Agarwal, Cris Cristina and Sheila Dugan were the Code for America fellows who developed RecordTrac with Oakland in 2013. Also part of the 2013 Code for America cohort, but not part of RecordTrac's creation, were Manik-Perlman, Andy Hull, and Reed Duecy-Gibbs. In late 2014, the latter three announced plans to launch NextRequest, a hosted version of RecordTrac with reworked code (Kanowitz, 2015): "What we've done with NextRequest is build upon the immense amount of work and learning that went into RecordTrac, updating the architecture in order to make the system accessible to governments of all sizes" (Hull, Manik-Perlman \& DuecyGibbs, 2014). Essentially, the open-source system became a civic tech startup, with investors ("NextRequest," n.d.) and a break-even projection of June 2016 (Matter Ventures, 2015).

Oakland signed on in 2017, stating that "as a company that grew out of the Code for America fellowship, NextRequest is uniquely aligned with our philosophy, values and workflow around transparency and records management" (City of Oakland, n.d.).

The cloud-hosted multi-tenant application relieves agencies of management demands because the company handles all costs of hosting, support, maintenance, and software upgrades (Phillips, 2016). The company provides a free version for small entities that receive 120 or fewer requests per year, and "Enterprise" packages of varying costs to other agencies. When NextRequest launched, the typical range was $\$ 2,000$ to $\$ 50,000$ per year depending on agency size (Matter Ventures). The Rhode Island Office of the General Treasurer was quoted $\$ 3,000$ per year and signed on. San Diego is paying $\$ 28,000$ for the current fiscal year. The State of Iowa pays about $\$ 77,500$ per year.

On the agency side, the system offers a centralized cross-departmental dashboard where employees can log and track requests, including assigning them to particular staffers, flagging them for legal review, communicating internally and externally about the request, logging time 
spent, filing an invoice for costs, and uploading documents of unlimited file size. Staffers are notified when they are assigned to handle a request and are reminded about the request as the due date approaches. Each request has an audit trail showing how it was handled, and staffers can run reports using various filters (for example, one could automatically generate a biweekly report of all overdue requests). Integrated redaction and payment tools are available for additional fees.

On the public side, users $\log$ into the system and file their request through a dashboard. They're given the name and contact information of the staffer(s) handling their request, communications and status updates about the request, and responsive documents. The system tries to avert requests for information already posted online. When a keyword like "budget" is typed into a request field, a yellow banner appears providing a link to existing budget information. Or if a record is requested that is housed with another agency, the system might flash a message to the user directing them to that agency.

As RecordTrac did, the system can provide a public, searchable repository of responsive documents from previous requests; this, in fact, was an initial selling point for the NextRequest system under a "release to one, release to all" ethos - a living archive that provides information before it even needs to be requested. It also coincides with the open-data trend in which agencies across the country are proactively publishing information that can be freely accessed, used, and redistributed in digital form (Noveck, 2016). As of 2017, 105 cities had adopted formal open-data policies that systematize proactive record release, 28 of which adopted policies in that year alone (Stern, 2018, p. 5). As NextRequest's Chief Operating Officer Duecy-Gibbs said, "The old way of doing things isn't viable anymore. We want to help local governments publish info out proactively, and give a way to help people access without having to ask" (Opsahl, 2016, para. 8).

NextRequest has become popular enough that MuckRock noted in March 2018 that part of its recent work included continuing to "tweak and improve MuckRock integration with agencies that use NextRequest portals" (Morisy \& Kotler, 2018, para. 4). In 2016, the Sunlight Foundation nodded to RecordTrac and NextRequest in listing recommendations for improving the federal Freedom of Information Act, suggesting that the U.S. government build FOIA software "with the people who make requests and process them. Oakland's RecordTrac is a useful model for improving the FOIA process. The national success of PostCode's NextRequest, which built upon that code, is worth studying and scaling" (Howard, 2016, para. 13).

That same year, the Center for Digital Government cited NextRequest as a factor in awarding third place to Sacramento County among its 2016 Digital Counties Survey winners. "A commitment to transparent operations can be seen in several new projects that have come to light in Sacramento County in the past year," including the request portal (Wood et al., 2016, para. 6).

\section{The case for trust}

As the 2017 Knight report suggests, people want better digital tools from their governing institutions. In a 2014 survey of 1,095 voting-age Americans, 62 percent said they would have more confidence and trust in government if offered improved digital services. Seventy-two percent said they would be more willing to engage with government, and an equal number said they would feel more overall satisfaction with government (Accenture, 2014, p. 15).

NextRequest's creators promote the portal as a mutually beneficial means of improving the relationship between individual and institution. In early 2016, Manik-Perlman appeared on a podcast called GovLove, produced by Engaging Local Government Leaders (ELGL). She described in detail the various benefits of the portal, including the ability to avert requests for 
already published information, the streamlined, customizable workflow management, safeguards against inadvertent publication in the form of a pop-up verification window, and above all, the transparency of allowing the public to see the work staffers are doing via tracking software. Seeing that work helps restore trust between the public and government, she said. "That's what's most important to us, is this sort of increase between empathy and trust, because government is us" (Wyatt, 2016). Later that year, on a different podcast, she reiterated that point: "Ultimately I think that the work we're doing is really about rebuilding trust between the public and government" (Phillips, 2016). One year prior, she told Politico she was already seeing a shift in the dynamic between citizen and institution as a result of her company's system:

People are entitled to request certain information from the government, and the government just hasn't had the tools they need to make it a simple process. The thing that's been especially interesting is seeing the tone of the discourse and the tone of the relationship between the public and the government change. ("The 60-second interview," 2015)

In an interview with The Daily Northwestern in 2016, COO Duecy-Gibbs said the company hoped to "change the tone of the relationship between the government and the public around access to information. It's very adversarial and it doesn't need to be. Technology is one way to make this a win-win for both employees and citizens" (Opsahl, 2016, para. 10).

This type of messaging speaks to the concept of operational transparency, in which ofthidden processes are made more visible to citizens as a means of increasing engagement and improving public perception. Research by Buell, Porter, and Norton (2018) for a Harvard Business School working paper suggests that the more an agency "shows its work" by providing a public view of its operations, the more people will trust and engage with that agency. In partnership with the city of Boston, they utilized a system not unlike NextRequest to test the correlation between transparency and trust. Selected Boston residents in a "blind" condition (Group 1) were shown a tally of resident-submitted service requests for issues such as illegal graffiti, potholes, and litter. Other residents in a "functional transparency" condition were shown a photo, address, and description of the issue, along with a timestamp indicating when it was submitted and the status of service. Results showed that Group 2, the "participants observing transparency into the work that government was doing, perceived the government more favorably than participants who did not observe the work" (p. 14).

With that in mind, this research aims to assess the effects of NextRequest and other PRR platforms both at the level of functionality for agencies and, in a broader sense, the perceived overall relationship with citizens because of increased transparency.

\section{Methodology}

This survey, based on a convenience sample of public record custodians, is meant to collect experiences and opinions among a cross-section of municipalities as such portals increasingly become part of civic life. This is evaluation research, designed to ascertain the effects of a change, but it is not meant to provide a representative sample reflecting all types of agency user experiences with online PRR portals.

A link to an online Qualtrics survey was distributed June 12-15, 2018, via email to publicrecords officers at 86 municipalities identified through a Google URL reverse-search as having NextRequest or GovQA records portals. The link was also shared via the social media channels of the National League of Cities, and emailed to the presidents of all state municipal clerks' 
associations in the U.S., with a request to forward to their members. Respondents were asked their names, titles, and jurisdictions. Though some declined to provide their names, all but one of the jurisdictions were identified by name and all were verified through Qualtrics location data, and they represent geographic diversity on a national scale, with concentrations in particular states where the association presidents opted to forward the link. Responses were accepted until March $25,2019$.

The survey consisted of 23 questions, including 6 identification/demographic queries, 13 multiple-choice questions primarily with item-specific response options, and four text-entry questions in which respondents were invited to elaborate or provide descriptions. Text-entry responses were evaluated for similarities and grouped accordingly to identify trends.

\section{Findings}

Of 127 respondents, 73 (57 percent) said their agencies do not use an online PRR portal while 54 (43 percent) said theirs do. Among those that do have online portals, answers ranged as to how many requests come to the agency each month, with a tendency toward higher volume: more than 60 requests per month (43 percent); 20 to 60 requests per month (33 percent); fewer than 20 requests per month ( 24 percent). All but 10 of the 73 who do not have online portals said they receive fewer than 20 records requests per month, suggesting the need for technology is correlative with the demand for public records. One respondent from a municipal fire and medical agency in Arizona wrote that he is interested in an online system for easier payment and better coordination across departments, but "our volume does not yet justify the cost."

All but three of total respondents, and all respondents who have an online PRR portal, said they are the ones who manage public-records requests for their agency, positioning them as reliable sources of information about their records request and fulfillment systems. Among those who have an online portal, NextRequest (50 percent) and GovQA (20 percent) were the most common providers named by respondents, but a series of other providers/systems were identified under "Other": JustFOIA (named by four respondents), SeamlessGov, OnBase, AgendaQuick, iCompass, QAlert, Vision, RecordTrac, CivicPlus, and three internally created systems.

Online portals rated highly among those who have them, with 72 percent saying they were "extremely satisfied" and 19 percent "somewhat satisfied." Several reasons were provided in written responses, sometimes more than one within a single response, with some trends identifiable across jurisdictions. The three most common reasons, listed by frequency of mention, are:

1. Centralization/consolidation of request management: The ease of centralizing management across departments and having one main hub, resulting in more efficient workflow, was cited 30 times as a benefit of an online portal.

2. Tracking: Twenty-one responses cited automated tracking of requests, with an emphasis on internal tracking for agency staff.

3. Ease of use for requesters: Twelve answers cited ease of use, increased access, and an overall better experience for members of the public.

Other benefits listed include speed, transparency, compliance, cost, redaction tool, and proactive release, in that order.

Nine percent of respondents said they were "neither satisfied nor dissatisfied" with their portals. None reported dissatisfaction. Respondents were also asked to name the greatest disadvantage or challenge of having an online PRR portal. Ten said they could find no 
disadvantage. Of those who provided answers, the three most common issues cited, in order of frequency of mention, were:

1. System limitations: Twelve respondents named various system-specific limitations, including lack of mobile access, manual uploading of emailed or hardcopy requests and, in the case of OnBase, lack of a payment module.

2. Digital divide: Seven answers mentioned various challenges around requesters' reluctance or inability to use a digital system. A respondent in one city (population 180,000) reported "some user-friendliness issues. Tutorials and 'how-to' explanations are not helpful for individuals in our municipality who are not tech savvy and have issues learning new technologies."

3. Staff buy-in and requester abuse were each cited five times as concerns. One respondent cited "revenge requests" as a problem, in which the ease of use prompts requesters to file frivolous requests out of anger at a particular department. A second agency originally published all requests and responsive records "but shut public access down due to irresponsible use by some community members." In a third jurisdiction, records requests were published to the portal that were in fact not requests, but advertisements for business loans.

Other disadvantages listed include system bugs, slow bandwidth for uploading, and the cost of additional modules.

Nearly 41 percent of respondents with an online records portal, 22 of 54, reported receiving more requests since adopting the portal. One respondent noted that in her city, "the number of requests are rising regardless of technology, but tech helps us respond more efficiently." Only one respondent to this survey said it takes more time to fulfill requests with a portal in place. Many more, 29, said it take less time to fulfill a request, and 20 said it takes about the same amount of time. Twenty-one said the costs associated with fulfilling requests are about the same, compared with 13 who said costs have decreased, five who reported an increase, and 14 who didn't know whether there was any change.

The portals rate highly among respondents when it comes to ease of use for agency staff and the overall effect on internal processes. Seventy-two percent said the portals are "extremely easy" for agency staff to use, and 67 percent said the portals have "vastly improved" the internal process while another 22 percent said they "somewhat improved" the internal process. No respondents stated that the portals are difficult to use or that they have adversely affected internal processes.

On the external side, such as interaction with members of the public, respondents also reported improvement. Fifty-seven percent reported that the portals "vastly improved" the external process of working with requesters, while 26 percent said they "somewhat improved" the process. No one reported adverse effects on the external side.

Respondents were then asked how the portals affected the "overall relationship" between their agency and members of the public. This is broader than the external process and gets at the stated goal of services like NextRequest - to improve the relationship between government and citizen. Twenty-two percent said the relationship was "vastly improved," while 43 percent said it was "somewhat improved." Twenty-six percent reported no real difference. No one reported adverse effects on the relationship, but five respondents ( 9 percent) checked "Other" and wrote answers such as "too soon to tell" or "I was not here before implementation." There were no discernible trends when it came to linking these responses to providers. In other words, the choice 
of provider (NextRequest, GovQA, JustFOIA or the others) did not seem predictive in determining how respondents viewed the effect on the overall relationship with the public.

Respondents were asked to elaborate via text entry on whether/how their portals have affected their agency's overall relationship with the public, and they provided a range of answers. Most continued to focus on process-level improvement for users, including easier submission, faster service, and increased transparency. Some commented on how this has positively affected the relationship with constituents: "I believe the portal has improved the relationship between the public and the agency because it has made it easier to be transparent." Similarly, "a greater sense of trust from the public to the governmental body due to efficiency, time management, and a commitment to transparency."

Others used the space to describe new or continuing challenges related to the overall relationship with constituents. Some commonalities among responses include:

1. Lack of public awareness/interaction: Relationships with citizens can be hard to gauge. Likewise, some residents do not notice changes in service. Representative comments included:

- "The public does not seem aware of the change. In addition, we cannot require requestors [sic] to use a certain method of requesting (the Texas PIA only requires that the request be in writing, so can be lipsticked on a napkin, painted on a rock, email, anything in writing), so there's been no massive transfer in how requests are received."

- "a large majority of our request [sic] are from business entities seeking leads. Typically they are not located locally and do not benefit our residents or the public in general."

- "We haven't received direct feedback from citizens but hope that the ease of making a request and increased access to records will foster trust."

2. Heightened expectations: A faster, easier system has in some cases raised expectations among users. For example:

- "Some complex requests still take a long time to process. Customer expectations are for instant access."

- "Because the portal is 'live' requesters expect immediate responses which is problematic when public records officers are juggling multiple requests. The result is that they are suspicious of responses that are not "immediate."'

- "Easy access does not equate easy work, but gives impression [sic] to users that finding records is easy."

3. Technology/format concerns: One respondent noted that some residents prefer "the old way" of doing things. Other quotes:

- "Some people appreciate the responses electronically and other [sic] do not."

- "The Gov QA Records Request Portal requires customes [sic] to create accounts and $\log$ in. Not all are pleased with this. Some customers have trouble downloading productions or reading messages."

As previously mentioned, most respondents said they rarely, if ever, opt to make responsive documents publicly available. Of the 54 who reported having an online PRR portal, 24 said they never publish responsive documents for public view, while 11 said they rarely do. Fourteen reported sometimes or often sharing responsive documents, and only 5 said they always do. However, five respondents noted that they are considering or working toward making requests 
and/or responsive documents available to the public, in keeping with the "release to one, release to all" and open data trends.

Similar to those that don't publish responsive records, 26 agencies said they never publish the actual records requests, while 11 said they always do. Sixteen said they also make public the identities of requesters. Fourteen said they do not. Twenty-four said they will reveal requesters' identities only if that information is requested by PRR.

\section{Discussion}

Although the sample is but a fraction of the hundreds of agencies that use online PRR portals, let alone the nearly 90,000 local governments that exist in the U.S. by last Census count, this research suggests a strong favorable view toward PRR portals, with approximately 9 out of 10 records managers expressing satisfaction with them, 7 expressing extreme satisfaction. Likewise, approximately 9 out of 10 report improvement in their agency's internal process of managing and responding to records requests, with three-quarters of that group reporting vast improvement. Slightly fewer, 8 of 10 , report improvement in their external process of working with requesters, also with three-quarters reporting vast improvement. When it comes to the portals' effect on the overall relationship between citizen and institution, 6.5 of 10 report improvement. However only one-third of that group report a vastly improved relationship versus a somewhat improved relationship.

There could be several reasons for this deviation. The most obvious is that agency staff are primarily concerned with the job before them, and they operate from the perspective of managing complex PRR systems. The text-entry comments reflect this, as the majority of praise focuses on the centralization and efficiency of one digital hub for PRR processing. Ease of use for the requester is also frequently mentioned but less than half as often. As some express in their answers, they hope a more efficient system will result in higher user satisfaction, but that is the order in which the benefits flow - from agency to citizen.

Also, a digital platform can only do so much. Manik-Perlman made this point herself during the GovLove podcast. "It really is not just software, it's really a process. Technology is not going to solve other problems in process that an agency might have" (Wyatt, 2016).

A PRR portal, like any system, still relies on people to complete the work involved. One survey respondent noted this in describing the challenges she faces even with a portal: "To locate a record, it still requires corresponding with the department that is the custodian of the record. The lenght $[$ sic $]$ of the process is dependant [sic] upon the ablity [sic] of the staff to locate the record, not the request platform."

If there are flaws or failings in the realms of policy or personnel, a digital system might highlight those shortcomings and erode any gains in goodwill. Recall that the Harvard Business School paper on occupational transparency compared the responses of Group 1, the Boston residents were given only a tally of service requests, with those of Group 2, who received specific operational details. Yet a third group was provided all of that information, plus the substantial backlog of service requests that had not yet been resolved. The results showed that participants in Group 3 "were no more trusting of government nor more supportive of government programs" than those in Group 1 (Buell, Porter \& Norton, 2018, p. 14).

In the case of PRR portals, increased transparency can raise difficult policy questions, including what information should be shared and how to safeguard information that shouldn't be available. Would an agency bear greater liability if redactable information is accidentally included 
in a published document? Should requesters be identified? Just how much should an internal process be laid bare?

In spring 2017, Evanston, Illinois's newly elected city clerk, Devon Reid, opted to make public all requests and responsive documents on the city's NextRequest platform. That fall, city leaders voted to take the portal offline for review after the names of a juvenile and a sexual assault victim were made visible in published records (the victim's name was redacted in all areas of a police document except one, while Reid said he did not redact the juvenile's name because the 12year-old boy had spoken publicly and received media attention) (Bookwalter, 2017). In December 2017, the leaders unanimously approved a new policy that keeps all requests and responsive documents private, despite Reid's claim that making them public relieved his staff's workload (Bookwalter, 2018). As of March 2019, requests were once again visible on the site, dating back to October 2018, but responsive documents remain private, shared only with requesters.

Another consideration, albeit a waning one as digital natives predominate, is the reluctance or inability of some members of the public to use digital services. As one respondent noted, jurisdictions are still required to accept PRRs in various forms, including paper. Records managers in several agencies said they upload those requests to the portals to ensure internal tracking and provide an audit trail. But on the external side, any requester who is unable or unwilling to use the portal is not provided the same range of communication and service as those who are, potentially creating a disproportionate benefit. One of the challenges in the development of e-participation in government has been the inclusion of low-income, older, and technology-challenged citizens (Bailey \& Ngwenyama, 2011), and this area is no exception.

Potentially more consequential than a citizen's distance from digital, either voluntary or involuntary, is one's fervent embrace of it. As reflected in the survey, several agencies are dealing with more requests as the portals - not to mention nongovernmental services like MuckRock make the request process easier and faster.

San Diego provides an illustrative example. Ten years ago, in 2009, the city received 344 requests under the California Public Records act, according to public records. That number grew to 1,210 in 2013, and ballooned once the city adopted a NextRequest portal in late 2015. Despite providing a searchable repository of responsive documents, the city received 2,928 requests in 2016, 3,792 in 2017, and 4,752 in 2018. City spokeswoman Katie Keach said staffers were striving to keep up:

but the fact is the NextRequest system has been extremely popular because of how easy it is to use and we've seen a significant increase in requests over the past couple years as a result. The volume, complexity and number of departments involved in the request can all contribute to the amount of time it takes to collect the responsive documents, conduct a legal review if necessary, and then distribute to the requester. (Schroeder, 2017, para. 9)

Reid, Evanston's city clerk, also attributed an increase in PRRs to the digital portal, now averaging about 100 per month compared to 50 per month pre-portal (Kanowitz, 2017):

I did notice that during the period we took the NextRequest system down to have a review of it, that we actually decreased the number of FOIAs that were coming in, so having a site that is easily accessible for folks actually increases the requests. (Baim, 2017, para. 11) 


\section{Conclusion}

These findings reflect a strongly positive view of the effects and efficacy of online PRR portals by record custodians, with the greatest derived benefits for internal processes and agency staff. External processes are also improved, though slightly less so. Improvement is also reported in the overall relationship between public and agency, but to an even lesser degree.

This could be for several reasons, including insufficient metrics for measuring that relationship or an overall difficulty in communicating with citizens beyond process-level interactions, plus tangible factors such as heightened expectations, a reluctance or inability to embrace digital systems among some constituents, increased demand that can strain agency resources, and other challenges. In other words, online PRR portals appear to significantly ameliorate a longstanding pain point, but could raise other challenges unique to digitized, transparent systems, challenges that require a rethinking of policies and processes. So far, it appears the benefits outweigh drawbacks for agency staffers.

This is only a step toward what should be a full examination of online PRR portals. This research was done with the employees who work with and manage these portals on the agency side, so the views reflected will naturally skew toward their priorities. Clearly more can be done to gauge the requester experience with these portals, including qualitative and quantitative data collection. Civic tech companies earn government clients by promising cost-savings, efficiency, and solutions, but also quite often an improved relationship with citizens. Given the ramifications of a system that operates to guarantee and preserve transparency, an underpinning of any healthy democracy, that side of the equation deserves further study as more and more agencies adopt online PRR portals. 


\section{References}

2019 GovTech 100. (n.d.). Government technology. Retrieved from https://www.govtech.com/100/2019

About MuckRock. (n.d.). MuckRock. Retrieved from https://www.muckrock.com/about

About OpenRECORDS. (n.d.). OpenRECORDS. Retrieved from https://a860openrecords.nyc.gov/about

Accenture. (2015). Digital government: Your citizens are ready, willing... and waiting. Retrieved from https://www.accenture.com/t20170228T002251Z_w__usen/_acnmedia/Accenture/Conversion-

Assets/DotCom/Documents/Global/PDF/Dualpub_16/Accenture-Your-Digital-CitizensReady-Willing-Waiting-2.pdfla=en

America's Best Open FOIL Web Site: Oakland's RecordTrac. (2014, February 18). Reinvent Albany. Retrieved from https://reinventalbany.org/2014/02/americas-best-open-foil-website-oaklands-recordtrac

Bailey, A., \& Ngwenyama, O. (2011). The challenge of e-participation in the digital city: Exploring generational influences among community telecentre users. Telematics and Informatics, 28(3), 204-214.

Baim, N. (2017, November 8). Evanston residents urge city clerk to adjust FOIA process. The Daily Northwestern. Retrieved from https://dailynorthwestern.com/2017/11/08/city/evanston-residents-urge-city-clerk-adjustfoia-process

Buell, R. W., Porter, E., \& Norton, M. I. (2018). Surfacing the submerged state: Operational transparency increases trust in and engagement with government. Retrieved from the Harvard Business School website: https://www.hbs.edu/faculty/Publication\%20Files/14034\%20(5) 92766f66-c1b7-459d-825f-fe9fc1231197.pdf

Capeloto, A. (2014, October 27). This open-source app could make the FOI process less terrible. Columbia Journalism Review. Retrieved from

https://archives.cjr.org/united_states_project/recordtrac_making_the_foia_process_less_t errible.php

City of Oakland. (n.d.). Justification: NextRequest. [Internal memo].

Cuillier, D. (2017). Forecasting freedom of information. Retrieved from the Knight Foundation website: https://knightfoundation.org/reports/forecasting-freedom-of-information

Eil, P. (2016, July 3). MuckRock's approach is working, one FOIA at a time. Boston. Retrieved from https://www.bostonmagazine.com/news/2016/07/03/muckrock-foia-turns-50

Fretwell, L. (2014, January 21). 2013 GovFresh awards winners. GovFresh. Retrieved from https://govfresh.com/2014/01/2013-govfresh-awards-winners

Higgins, P. (2015, May 4). Oakland's awesome public records request system. Parker Higgins dot net. Retrieved from https://parkerhiggins.net/2015/05/oaklands-awesome-publicrecords-request-system/

Howard, A. (2016, June 24). 7 ideas to make the Freedom of Information Act better. Sunlight Foundation. Retrieved from https://sunlightfoundation.com/2016/06/24/7-ideas-to-makethe-freedom-of-information-act-better

Hull, A., Manik-Perlman, T., \& Duecy-Gibbs, R. (2014, October 27). Welcome to NextRequest, the open public records portal. Retrieved from 
http://blog.postcode.io/post/101138657517/welcome-to-nextrequest-the-open-publicrecords

International City/County Management Association (2017). 2017 Government technology

solutions survey. Retrieved from

https://icma.org/sites/default/files/2017\%20Government $\% 20$ Technology $\% 20$ Solutions $\%$ 20Survey.pdf

Kanowitz, S. (2015, August 6). Public record requests made easy (for government). GCN.

Retrieved from https://gcn.com/articles/2015/08/06/nextrequest-publicrecords.aspx?admgarea $=\mathrm{TC} \_$Cloud

Kanowitz, S. (2017, February 28). Digging out from under records requests. GCN. Retrieved from https://gcn.com/Articles/2017/02/28/managing-records-requests.aspx?Page=1

Knight Foundation and Rita Allen Foundation. (2017). Scaling civic tech: paths to a sustainable future. Retrieved from https://s3.amazonaws.com/kf-site-legacymedia/feature_assets/www/civictechbiz/assets/Scaling_Civic_Tech_final.pdf

Manik-Perlman, T. (2017, March 28). City of Oakland NextRequest proposal.

Matter Ventures (2015, June 23). Matter Four Demo Day NextRequest [Video file]. Retrieved from https://vimeo.com/131581512

Morisy, M., \& Kotler, M. (2018, March 12). MuckRock release notes: Confidently leaping ahead into Sunshine Week. MuckRock. Retrieved from https://www.muckrock.com/news/archives/2018/mar/12/mrn-sw

NextRequest (n.d.) Crunchbase. Retrieved from https://www.crunchbase.com/organization/nextrequest\#section-overview

Norris, D. F., \& Reddick, C. (2011). Electronic government 2011. Retrieved from the International City/County Management Association website https://icma.org/sites/default/files/302947_EGovernment $\% 202011 \% 20$ Survey\%20Summary.pdf

Noveck, B. S. (2016). Is open data the death of FOIA? Yale Law Journal, 126(2), 273.

Opsahl, R. (2016, February 1). Evanston launches online public records portal, database. The Daily Northwestern, p. 1.

Phillips, M. (2016, July 12). GovTech: Disrupting government through access and transparency. [Audio podcast]. Retrieved from https://www.sparkpluglabs.co/powerfulconversations/episode 53

Rumbul, R., \& Shaw, E. (2016). [The role of civic technology in e-government evolution]. Unpublished raw data.

Rumbul, R., \& Shaw, E. (2017). Civic tech cities. Retrieved from mySociety website: http://research.mysociety.org/publications/civic-tech-cities

Schroeder, L. (2017, November 22). Access to city records can take weeks with new online portal. The San Diego Union-Tribune. Retrieved from https://www.sandiegouniontribune.com/news/watchdog/sd-me-nextrequest-database2017122-story.html

Shaw, E. (2016, April 11). Why civic technologists should still care about e-gov. Civicist. Retrieved from https://civichall.org/civicist/why-civic-technologist-should-still-careabout-egov

Stern, A. (2018). Open data policy and FOI law. Retrieved from the Sunlight Foundation website: http://sunlightfoundation.com/wp-content/uploads/2018/10/alena-white-paperPDF.pdf 
The 60-second interview: Tamara Manik-Perlman, C.E.O. and cofounder of NextRequest. (2015, July 29). Politico. Retrieved from https://www.politico.com/media/story/2015/07/the-60second-interview-tamara-manik-perlman-ceo-and-cofounder-of-nextrequest-004006

Wang, S. (2016, November 29). Twice the FOIA fun: MuckRock bulks up its records request resources with the free FOIA Machine tool. Nieman Lab. Retrieved from http://www.niemanlab.org/2016/11/twice-the-foia-fun-muckrock-bulks-up-its-recordsrequest-resources-with-the-free-foia-machine-tool

Wood, C., Knell, N., Pittman, E., Newcombe, T., Eidam, E., McCauley, R., \& Mulholland, J. (2016, July 20). Digital counties survey 2016: Winners make collaboration, innovation, civic engagement top priorities. Government Technology. Retrieved from https://www.govtech.com/dc/articles/Digital-Counties-Survey-2016-Results.html?page=2

Wyatt, K. (2016, February 5). Local government technology, NextRequest and Seneca Systems. [Audio podcast]. Retrieved from https://medium.com/@ELGL50/podcast-intersection-oflocal-government-and-technology-cd90ca5a3ba0 